\title{
Accounting Conservatism in Fraud Firms: An Empirical Investigation*
}

\author{
Keith Jones \\ Assistant Professor \\ George Mason University \\ kjonesm@gmu.edu \\ Gopal Krishnan \\ Professor \\ Lehigh University \\ gkrishn1@gmu.edu \\ Mikhail Pevzner** \\ Assistant Professor \\ George Mason University \\ mpevzner@gmu.edu \\ Partha Sengupta \\ Associate Professor \\ George Mason University \\ psengupt@gmu.edu
}

We examine whether Ball and Shivakumar (2006) and Basu (1997) models of conservatism identify fraud firms as anti-conservative. We show that both models do so to some extent, but Ball and Shivakumar model results are stronger. We further show that these results are driven by firms committing largest frauds as a percentage of firms' assets. Our results are important to academics who use conservatism measures in their studies, and to policy makers who seek to assess usefulness of conservatism to capital markets.

**Corresponding Author, 4400 University Drive, MS5F4, Fairfax, VA 22030 


\section{Accounting Conservatism in Fraud Firms: An Empirical Investigation*}

We examine whether Ball and Shivakumar (2006) and Basu (1997) models of conservatism identify fraud firms as anti-conservative. We show that both models do so to some extent, but Ball and Shivakumar model results are stronger. We further show that these results are driven by firms committing largest frauds as a percentage of firms' assets. Our results are important to academics who use conservatism measures in their studies, and to policy makers who seek to assess usefulness of conservatism to capital markets.

Key Words: Conservatism, Basu Model, Ball and Shivakumar Model, Fraud

Data Availability: All data employed in this study are commercially available from sources described in the text. 


\section{Introduction}

In this study, we examine whether 1) two popular conditional conservatism models, namely the Basu (1997) and the Ball and Shivakumar (2006) models correctly identify a lack of conservatism among firms known to have committed financial statement fraud, and 2) whether these models indicate changes in fraud firms' conservatism policies in the years following the discovery of the fraud.

These research questions are important for several reasons. First, the debate on whether accounting conservatism is important is still very much ongoing (Watts (2003)). In light of FASB's continued orientation towards further expansion of the role of fair value, potentially at the expense of reducing levels of firms' accounting conservatism, it is important to once again identify whether the stock market participants view conservatism as an important aspect of financial statement quality. Our paper addresses this concern by investigating whether fraud firms change their conservatism policies, in the years following the fraud's discovery. Second, within academic literature, we have seen a lively debate on how to measure accounting conservatism correctly. Here the debate centers primarily on whether the Basu (1997) model (hereafter the Basu model) indeed measures firms' conservatism. Opponents of the Basu model argue that it is econometrically biased and is also unstable in time-series estimations (e.g. Givoly et al., 2007, and Deitrich et al, 2007). Proponents of the Basu model argue that the Basu model has a good economic motivation and exhibits theoretically expected properties, such as a positive correlation with market-to-book ratio over longer time horizons (e.g. Roychowdhury and Watts, 2007, and, Ball and Kothari, 2008). We contribute to this debate by examining whether the Basu model and its recent counterpart, Ball and Shivakumar (2006) model (hereafter the Ball and Shivakumar model), correctly identify a lack of conservatism among fraud firms in years when 
the fraud was committed. Firms that commit fraud are by definition taking actions to boost earnings and assets aggressively and therefore we would expect these firms to be less conservative over the fraud period. A good model of conservatism should pick up this change in conservatism. However, if the models fail to pick up the change in conservatism over the fraud period, one may question the usefulness of these conservatism models to researchers and practitioners.

Our research is based on a sample of fraud firms with at least one year of fraudulently misstated financial statements over the period 1987-2007. In all, we obtain 352 fraud observations. We hand-collect pre-restatement data for these firms to measure their fraud period conservatism levels. We also obtain financial data for a period of five years surrounding the fraud year, with two pre-fraud years and two post-fraud years, in order to examine if and how conservatism changes for these firms over time. Finally we also identify a matched sample of non-fraud firms which includes all firm-year observations that match the fraud firms on the basis of two-digit SIC codes and year in order to examine how conservatism in these firms compare to the fraud firms. We examine two measures of conservatism - the Basu measure and the Ball and Shivakumar measure and examine how these measures compare across the two samples and also over time.

Our analysis yields a number of interesting findings. With respect to Ball and Shivakumar model, our results indicate that fraud firms are 1) less conservative in the fraud period than in both pre-fraud and post-fraud period, and 2) conservatism of fraud firms increases following the fraud's discovery. Furthermore, we show that these results are driven by fraud firms which had the highest restatement level of fraudulent net income numbers. However, for the Basu model, our results are weaker. It fails to identify fraud firms as being less conservative in the fraud 
period compared to the pre-fraud and post-fraud periods. In comparison to the matched sample we only find weak evidence of a slight increase in conservatism in the Basu model in post-fraud period. Finally the Basu model picks up a decrease in conservatism in post-fraud period, contradicting our results with respect to Ball and Shivakumar model.

Our paper proceeds as follows. Section 2 describes our motivation and hypotheses. Section 3 describes our sample. Section 4 discusses our results. Section 5 concludes.

\section{Hypotheses development}

Conservatism is a widely-studied topic in empirical accounting literature. This literature distinguishes between two kinds of conservatism: unconditional and conditional (Beaver and Ryan, 2005). Unconditional conservatism is an unconditional downward bias in accounting earnings and book values. Expensing of R\&D is an example of unconditional conservatism. Because it reduces the value of firms' net assets, unconditional conservatism results in the higher market-to-book ratios. On the other hand, conditional conservatism is characterized by the asymmetric timeliness in recognition of economic gains and losses in accounting earnings. Asymmetric timeliness implies that recognition of gains requires a greater degree of verification than the recognition of losses. A good example of that is the recognition of contingent losses versus the non-recognition of contingent gains. Under US GAAP, contingent liabilities are recognized when probable and can be reasonable estimated, but contingent gains are not recognized until contingency is fully resolved, i.e. gains are no longer contingent.

Several measures of conservatism have been widely used in the literature: Basu's (1997) asymmetric timeliness measure, Ball and Shivakumar's (2006) accruals-cash flows measure, and Givoly and Hayn's (2000) non-operating accruals and relative skewness/variance of cash flows 
measures. Our focus on this paper is on the Basu (1997) and the Ball and Shivakumar (2006) measures because of their applicability to fraud firms.

Basu (1997) argues that the asymmetric recognition of economic gains and losses in accounting earnings leads to an asymmetric relation between stock returns and accounting losses and accounting gains. Assuming market efficiency, stock returns will incorporate both economic gains and losses, while accounting earnings will incorporate economic losses relatively early compared to economic gains. Hence, Basu shows that stock returns exhibit higher correlation with accounting losses, than with accounting gains. Because of its intuitive appeal, the Basu model has been incorporated in several studies of economic determinants of, demand for, and economic consequences of the use of accounting conservatism (Ball and Kothari, 2008).

Lately, the Basu model has been criticized for being econometrically unstable. Thus, Dietrich et al. (2007) argue that the asymmetric timeliness documented in Basu (1997) is an outcome of biased t-statistics, and Givoly et al. (2007) document that the Basu measure understates the degree of accounting conservatism due to temporal aggregation of earnings and returns and due to differences in informational flow across firms. ${ }^{1}$ Givoly et al. also show some results suggesting that asymmetric timeliness documented by Basu (1997) could be driven by economic events unrelated to accounting, such as being a target of acquisition or a lawsuit. ${ }^{2}$ Beaver et al. (2008) also show that in a simultaneous equation setting, modeling Basu (1997) regression and Hayn (1995) regression $^{3}$, the Basu (1997) asymmetric timeliness coefficient becomes insignificant.

\footnotetext{
${ }^{1}$ In particular, for firms with significant number of economic events, where the amount of information arrival is more gradual, conservatism appears to be under-stated. This suggests that Basu measure is biased against finding conservatism amongst larger firms.

${ }^{3}$ Basu (1997) is a reverse earnings returns regression and can be interpreted as just the outcome of the stock market assigning lower earnings multiple on less persistent accounting losses (Hayn (1995)).
} 
Ball and Kothari (2008) respond to the criticisms of the Basu model by showing that the model is economically well specified and is rooted in the research objective of identifying the relationship between accounting earnings and stock returns. Roychowdhury and Watts (2007) also show that another criticism of the Basu model, that asymmetric timeliness is negatively correlated with market-to-book ratio, disappears as the returns and earnings window is expanded. Hence, whether the Basu (1997) measure of conservatism is a good one is still debated in the literature.

Ball and Shivakumar (2006) suggest another measure of conservatism. They show that when cash flows are negative, accruals and cash flows have higher correlation because accruals capture expectations of future economic losses. This model has become recently more widely used because of its intuitive appeal. This model is particularly appealing to use in firms where stock returns data are not readily available, such as privately-held firms, to which the Ball and Shivakumar apply the model. ${ }^{4}$ In contrast to the Basu (1997) model whose validity has been widely examined, to our knowledge, the validity of the Ball and Shivakumar model has not yet been extensively tested..$^{5}$

Firms that commit financial statement fraud represent a particularly good setting to analyze the validity of the Basu and the Ball and Shivakumar measures. We focus solely on frauds that are income increasing because firms committing these frauds are least likely to be conservative. If the Basu and the Ball and Shivakumar models are well-specified, then we should expect these models to show that fraud firms are less conservative in years of the fraud. We choose to focus on these two measures of conservatism rather than include certain other measures such as those based on cumulative operating accruals or time series measures such as

\footnotetext{
${ }^{4}$ Moerman (2006), Jones et al. (2008), Ball, Bushman and Vasvari (2006), Pae (2007)

${ }^{5}$ Jones et al. (2008) investigate the relative model of discretionary accruals estimates produced by Ball and Shivakumar (2006) model.
} 
relative skewness and variances in cash flows or earnings because fraud often occurs over a relatively short period and the effects reverse subsequently so that its impact would be "washed out" over longer horizons. Also most frauds affect revenue recognition and asset capitalization (Beasley et al. 2009), and thus measures based on non-operating accruals may not be able to pick up the effects of fraud.ing accruals. Finally, the market-to-book ratio is another potential measure of conservatism but since many fraud firms are also growth firms and this has been used extensively in the literature as a important red flag to indicate fraud (Loebbecke et al., 1989; and Beneish, 1999) the market-to-book ratio would not be a good method to measure conservatism in a fraud setting.

Hence, our first hypothesis is as follows:

H1a: Fraud firms are less conservative than non-fraud firms according to the Ball and Shivakumar measure.

$H$ Hb: Fraud firms are less conservative than non-fraud firms according to the Basu measure.

We also expect that upon discovering of the fraud, fraud firms adopt more conservative accounting policies in the post-fraud period. Demand for conservatism arises from increased public scrutiny and increases in firms' litigation risk and information asymmetry, and prior research shows that firms experiencing such increases respond by becoming more conservative (Khan and Watts, 2007; Ball and Shivakumar, 2006). Moreover, firms that experience accounting frauds generally replace their managers, and it is likely that for reputational reasons these managers become more conservative. Moreover, fraud firms improve their corporate governance structures in post-fraud periods (Farber, 2005). Higher levels of corporate governance are associated with higher levels of accounting conservatism (Garcia Lara et al., 2007), further suggesting that conservatism levels should improve in the post-fraud years. This leads us to the next two hypotheses: 
H2A: Fraud firms are more conservative during the post-fraud periods in comparison to the prefraud period.

H2B: Fraud firms are more conservative than non-fraud firms during post-fraud periods.

We further expect that our findings in tests of Hypotheses 1 and 2 are affected by the magnitude of the fraud committed by a particular firm. If conservatism models we examine in our paper are effective in picking up the lack of conservatism of firms committing frauds of highest magnitudes should be deemed to be more anti-conservative in pre-fraud periods than firms that commit small frauds. A magnitude of ex-post earnings restatement is a measure of the level of fraud committed by a firm. Thus, we predict:

H3: Fraud firms with highest earnings restatement levels are less conservative than fraud firms with lower restatement levels.

In addition, if conservatism is a good way to address agency problems between managers and investors (Khan and Watts (2007), LaFond and Watts (2008)) and between managers and debtholders (Moerman (2008), Watts (2003)), then firms committing greatest levels of fraud should experience higher demand for ex-post conservatism than firms that commit smaller frauds. Thus, we expect:

H4: Firms with highest earnings restatement levels experience stronger increases in conservatism in post-fraud periods, than firms with lower levels of earnings restatements.

\section{Research design}

Our research design expands the Ball and Shivakumar model and the Basu model to incorporate the effects of fraud. We are interested in two types of comparisons: (i) a comparison of conservatism of fraud firms with that of non-fraud firms, and (ii) a comparison of 
conservatism across periods surrounding the fraud. We achieve this by combining the fraud firms with all other firms that have the same two-digit SIC codes as the fraud firms. This combined sample is explored over three different (but overlapping) sub-periods. The first subperiod includes the five years prior to the fraud and the fraud period. The second sub-period includes the fraud period and a post-fraud period of five years. Finally, the third sub-period includes the pre-fraud period and the post-fraud periods. Separate analysis of conservatism is conducted for each of these three sub-periods. The research design for tests of the Ball and Shivakumar model and the Basu model are described separately below:

\subsection{Tests using the Ball and Shivakumar Model}

The Ball and Shivakumar (2005) model's accrual model is of the following form:

$$
T A=\beta_{0}+\beta_{1} D C F+\beta_{2} C F+\beta_{3} D C F * C F+\gamma
$$

where,

$T A=\quad$ total accruals, defined as earnings before extraordinary items (data123) minus firm's cash flows (data308) for firm years after 1988 and later; for 1987 and earlier it is calculated using the Sloan (1996) approach.

$C F=\quad$ cash flows, defined as the difference between earnings before extraordinary items (data123) and a firm's accruals.

$D C F=\quad$ an indicator variable that equals 1 if $C F_{t}<0 ; 0$ otherwise.

$$
\begin{aligned}
T A= & \alpha_{0}+\alpha_{1} D C F+\alpha_{2} C F+\alpha_{3} D C F * C F+\alpha_{4} F R A U D P R D+\alpha_{5} F R A U D F R M+\alpha_{6} C F * D C F * F R A U D P R D \\
& +\alpha_{7} C F * D C F * F R A U D F R M+\alpha_{8} C F * D C F * F R A U D P R D * F R A U D F R M+\gamma
\end{aligned}
$$

where,

$F R A U D P R D=$ an indicator variable that equals 1 if the year represents a pre-fraud year, 0 if the year is a fraud year and 2 if the year is after the fraud year. 
FRAUDFRM = an indicator variable that equals 1 if the firm is a fraud firm; 0 otherwise.

We estimate equation (2) to examine potential differences in conservatism between the fraud and non-fraud firms and differences in conservatism over three periods: the pre-fraud period, the fraud period and the post-fraud period. In each test we compare two periods at a time. Therefore we use three panels of observations: (i) fraud firms and non-fraud firms in the pre-fraud and fraud periods, (ii) fraud firms and non-fraud firms in the fraud and post-fraud periods, and (iii) fraud and non-fraud firms in the pre-fraud and post-fraud periods. If fraud firms are less conservative than the non-fraud firms over the fraud period $\alpha_{8}$ should be negative.

To test Hypothesis 2, we re-run equation (2) including only the observations for Pre-fraud and post-fraud firm-years. Hypothesis 2 predicts that $\alpha_{8}>0$ in this sub-sample.

Hypotheses 3 and 4 involve examining the effects of the magnitude of the restatement. In order to conduct these tests we modify equation (2) to take the form:

$$
\begin{aligned}
T A= & \alpha_{0}+\alpha_{1} D C F+\alpha_{2} C F+\alpha_{3} D C F * C F+\alpha_{4} F R A U D P R D+\alpha_{6} R E S T A T E H+\alpha_{6} D C F * C F * F R A U D P R D \\
& +\alpha_{7} C F * D C F * F R A U D P R D^{*} R E S T A T E H+\gamma
\end{aligned}
$$

Where,

RESTATEH $=$ an indicator variable that equals 1 if the amount of income restatement (i.e., difference between originally reported earnings and restated earnings), deflated by total assets, is higher than the median value; 0 otherwise.

For Hypothesis 3, we restrict our sample to two subsamples: firm-years in pre-fraud and fraud periods, and firm years in fraud and post-fraud periods. For Hypothesis 4, we focus on firm-years in pre-fraud and post-fraud periods. For Hypothesis 3, our prediction is that $\alpha_{7}<0$. For Hypothesis 4 , our prediction is that $\alpha_{7}>0$. 
For Hypothesis 3, we restrict our sample to two subsamples: firm-years in pre-fraud and fraud periods, and firm years in fraud and post-fraud periods. For Hypothesis 4, we focus on firm-years in pre-fraud and post-fraud periods. For Hypothesis 3, our prediction is that $\alpha \Varangle<$. For Hypothesis 4, our prediction is that $\alpha_{7}>0$.

\subsection{Tests using the Basu Model:}

The standard Basu model estimates the reverse regression of earnings on market returns as follows:

$E A R N=\alpha_{0}+\alpha_{1} R E T+\alpha_{2} D+a_{3} R E T * D+\varepsilon$

where,

$E A R N=$ earnings before extraordinary items (data18), deflated by the prior period total assets,

RET $=\quad$ buy and hold stock return, cumulated starting three months after the beginning of a firm's fiscal year, and ending three months after the end of the company's fiscal year,

$D=\quad$ is an indicator variable that equals 1 when $R E T<0 ; 0$ otherwise.

We modify this model to include the effect of fraud as follows

$$
\begin{aligned}
E A R N= & \alpha_{0}+\alpha_{1} R E T+\alpha_{2} D+a_{3} R E T * D+\alpha_{4} F R A U D P R D+\alpha_{5} F R A U D F R M+\alpha_{6} R E T * D * F R A U D P R D \\
& +\alpha_{7} R E T * D * F R A U D F R M+\alpha_{8} R E T * D * F R A U D P R D * F R A U D F R M+\varepsilon
\end{aligned}
$$

As before, hypothesis 1 suggests that $\alpha_{8}$ should be negative.

For hypothesis 2 we restrict the sample to fraud firms only and re-estimate equation (5) including only pre-fraud and post-fraud periods. Our hypothesis 2 predicts that $\alpha_{8}>0$ in this subsample. 
Hypotheses 3 and 4 involve examining the effects of the magnitude of the restatement. In order to conduct these tests we modify equation (5) to take the form:

$$
\begin{aligned}
E A R N= & \alpha_{0}+\alpha_{1} R E T+\alpha_{2} D+a_{3} R E T * D+\alpha_{4} F R A U D P R D+\alpha_{5} R E S T A T E H+\alpha_{6} R E T * D * F R A U D P R D \\
& +\alpha_{7} R E T * D^{*} F R A U D O R D^{*} \text { RESTATEH }+\varepsilon
\end{aligned}
$$

For Hypothesis 3, we restrict our sample to two subsamples: firm-years in pre-fraud and fraud periods, and firm years in fraud and post-fraud periods. For Hypothesis 4, we focus on firm-years in pre-fraud and post-fraud periods. For Hypothesis 3, our prediction is that $\alpha_{7}<0$. For Hypothesis 4 , our prediction is that $\alpha_{7}>0$.

\section{Sample Selection}

Our fraud sample includes firms that fraudulently overstated annual earnings (i.e., the firm misstated earnings on at least one 10-K filing). While there are other types of fraud, overstatement of earnings is the most common type of fraud and is relates most clearly to a lack of conservatism. We did not include frauds that misstated quarterly data because the conservatism models in our study are designed to detect conservatism using annual data.

We identified our fraud sample from three sources. The first source is the COSO published report: "Fraudulent Financial Reporting: 1987-1997 - An Analysis of U.S. Public Companies". The COSO study investigated frauds that were identified in SEC's Accounting and Auditing Enforcement Releases (AAERs) issued during the period of 1987-1997. COSO identifies 204 fraud firms. Second, we performed our own search of AAERs issued during 1998-2007. We used "fraud" as a search term and identified an additional 268 fraud firms. Third, we identified another six firms by searching the popular press and the American Accounting Association Monograph on litigation involving Big4 auditors and their predecessor firms. From this 
combined sample of 478 observations, we excluded those firms that (i) didn't misreport at least one 10-K (e.g. fraudulent manipulated quarterly data only), (ii) committed non-financial frauds (e.g. insider trading, omitted disclosures, backdated options), (iii) did not manage earnings (e.g. reported sales on a gross rather than a net basis which increased sales and cost of sales by the same amount), and (iv) didn't have financial data available in Compustat or CRSP, or we are unable to locate company data (e.g. small firms or foreign companies). Our final fraud sample consists of 187 fraud firms. ${ }^{6}$ The procedures for identifying fraud firms are summarized in Appendix A. We then collect Compustat data for these firms for the fraud years we identify and 6 years before and after the fraud period. We use firm-years with all available Compustat data in our analysis. These data are further described in Table 1.

To test Hypotheses 1a, 1b and 2, we construct a matched sample of non-fraud firms by including all firms that did not commit fraud, with available data in Compustat in our control sample. We match these non-fraud firms with fraud firm sample on a firm year and 2 digit SIC code, and include all non-fraud firm-year observations with available data in our analysis. These data are further described in Table 1.

To test Hypotheses 3 and 4, we hand-collect the ex-post income restatement amounts for fraud firms, in addition to the data already used to test Hypotheses 1a, 1b and 2. Because restatement amounts are not available for all firms, our sub-samples are much smaller in size.

\footnotetext{
${ }^{6}$ In addition, we found that Compustat does not consistently report restatement data. It appears that if the restated data is available when Compustat personnel enter the data in their database, the restated data is entered and the fraudulent numbers are discarded. It does not appear that Compustat changes data upon restatements several years after the original data is entered in their database. Therefore, we compared Compustat data with the original 10-K filing to verify that the data in Compustat is the fraudulently reported numbers and not the restated data. We found that Compustat reports restated data for 36 of the 361 fraud firm-years in our fraud sample. We hand-collect the original fraudulent data for those 36 firm years. SEC filings are available on EDGAR beginning in 1994. SEC filings for selected companies are available on Lexis/Nexis for years prior to 1994 and we were able to locate data for several firms prior to 1994.
} 


\section{Results}

\subsection{Descriptive statistics}

Table 1 summarizes the descriptive statistics of the sample of fraud and non-fraud firms during pre-fraud period, fraud period, and post-fraud period. Several interesting patterns emerge. Consistent with expectations, earnings performance of fraud firms declines over time: median net income $(E A R N)$ changes from 0.06 to 0.04 to -0.03 between pre-fraud, fraud and post-fraud periods. ${ }^{7}$ This result is consistent with the other evidence in the literature suggesting that fraud firms overstate their earnings and experience declines in performance, subsequent to the fraud's discovery (e.g. Rosner, 2003). A similar pattern could be observed with respect to fraud firms' raw and abnormal stock returns (variables RET and BHAR respectively). Fraud firms' total accruals also experience declines through time, most notably in the post-fraud period, consistent with our expectation that fraud firms should become more conservative after the fraud's discovery. However, consistent with the possible accrual manipulation during fraud period, Fraud firms' cash flows remain similar through time. Interestingly, no such consistency could be observed for non-fraud firms: earnings, accruals and cash flows follow the same declining temporal patterns for these firms. Neither could we see a discernable pattern for stock returns of non-fraud firms. The analysis of the other variables reveals that fraud firms in our sample are somewhat different from the control non-fraud firms: fraud firms are slightly larger and have slightly less $\operatorname{debt}^{8}$, but are not significantly different with respect to their price-earnings ratio $(P E)$. Since these differences are not substantial, sample selection biases seem to be less of an issue here.

\footnotetext{
${ }^{7}$ Significant at 0.01 level using Wilcoxon test.

${ }^{8}$ Significant at 0.01 level using Wilcoxon test.
} 


\subsection{Tests using the Ball and Shivakumar model}

Table 2 summarizes our tests of whether the Ball and Shivakumar model detects differences in conservatism across fraud and non-fraud firms as well as across fraud and nonfraud periods. Our model allows the general coefficient of conservatism $D C F^{*} C F$ to vary both across firm types (fraud vs. non-fraud firms) and across time (pre-fraud, fraud, and post-fraud periods). The coefficient for $D C F^{*} C F^{*} F R A U D F R M$ captures the association between fraud firms and conservatism. Results reported in panels A, B and C, show that the fraud firms are less conservative than the non-fraud firms in all sub-periods as the coefficient for $D C F^{*} C F^{*} F R A U D F R M$ is negative and statistically significant in all regressions. More importantly, we are interested in understanding whether fraud firms are relatively less conservative than the non-fraud firms over the fraud period and this is examined by looking at the coefficient on variable $D C F^{*} C F^{*} F R A U D P R D^{*} F R A U D F R M$. We find the coefficient for this variable to be negative and statistically significant at the 0.01 level in panel A and positive and statistically significant in Panel B, suggesting that fraud firms are indeed less conservative than non-fraud firms in the fraud period compared to the pre or post fraud periods. Moreover, the results of panel $\mathrm{C}$ suggest that in the post-fraud period, fraud firms increase their conservatism substantially compared to the pre-fraud period, as the coefficient for $D C F^{*} C F^{*}$ FRAUDPRD*FRAUDFRM is positive and statistically significant in panel C..

We examine next whether the Ball and Shivakumar model detects differences in conservatism across high and low restatement firms. The results of this analysis are presented in Panel B of table 2. We only include fraud firms in this analysis (no control sample), as we are interested in how conservatism varies with restatement size among fraud firms. Our primary 
variable of interest is $D C F^{*} C F^{*} F R A U D P R D^{*} R E S T A T E H$. Our results, suggest that conservatism indeed varies with the size of the restatement. In our comparison of the pre-fraud period with the fraud period, the coefficient on $D C F^{*} C F^{*} F R A U D P R D * R E S T A T E H$ is negative and significant at the 0.01 level showing that high restatement firms are significantly less conservative than the other fraud firms in the fraud period. This result suggests that the corresponding result in Panel A of Table 2 is driven by high restatement firms. Furthermore, the results indicate that there is an improvement in conservatism of fraud firms in post-fraud period that is driven by the high restatement firms as the coefficient for $D C F^{*} C F^{*} F R A U D P R D * R E S T A T E H$ is positive and statistically significant.

These results, taken together, suggest that: (i) the Ball and Shivakumar model correctly identifies the lack of conservatism among fraud firms during the fraud period, compared to the general population; (ii) the lack of conservatism is primarily driven by high restatement firms, and (iii) the fraud firms increase their conservatism in post-fraud period, in response to the discovered fraud. The latter result also appears to be driven by high restatement firms.

\subsection{Tests using the Basu Model}

Next we go on to examine the degree to which the Basu model picks up differences in conservatism across fraud and non-fraud firms and over time. The research design mimics the tests used for the Ball and Shivakumar model. Panel A of table 3 reports the results of tests examining whether the fraud firms show a lack of conservatism over the fraud period. Compared to the results for the Ball and Shivakumar model the results using the Basu model are weaker. First, the coefficient for $D^{*} R E T^{*} F R A U D F R M$ is not statistically significant in panel A suggesting no difference in conservatism in the fraud and non-fraud firms (the coefficient is 
statistically significant in pabnels B and C though). In order to examine whether fraud firms are less conservative than non-fraud firms in the fraud period we examine the coefficient for $D^{*} R E T^{*} F R A U D P R D^{*} F R A U D F R M$ and as in the case of the Ball and Shivakumar model, the coefficient for this variable is positive and statistically significant suggesting that that fraud firms are indeed less conservative than the non-fraud firms in the fraud period. Finally with respect to the comparison of conservatism of the fraud firms over time, the coefficient on variable $D^{*} R E T^{*} F R A U D P R D^{*} F R A U D F R M$ is positive with a t-value of 1.63 , which is marginally significant in a one-tail test showing weak evidence of an improvement in conservatism in the post-fraud period.

We repeat our analysis of high restatement firms for the Basu model and the results are reported in Panel B of Table 3. Again, our primary variable of interest is the regression coefficient on variable $D^{*} R E T^{*} F R A U D P R D^{*} R E S T A T E H$. We find that for high restatement fraud firms are significantly less conservative than the other fraud firms in fraud period vs. prefraud period (the coefficient is negative and statistically significant). However, with respect to pre-fraud and post-fraud period comparison, we find that the Basu model picks up a decrease in conservatism for high restatement firms, a result opposite to that of the Ball and Shivakumar model (see Panel B of Table 2).

\section{Conclusion}

We examine whether the Basu (1997) model and the Ball and Shivakumar (2006) model identifies accounting firms committing fraud as anti-conservative. We find that the Ball and Shivakumar model shows that fraud firms are less conservative than non-fraud firms in fraud period as compared to pre-fraud period. Moreover, the Ball and Shivakumar model shows that fraud firms' conservatism increases in post-fraud period as compared to non-fraud firms. For the 
Ball and Shivakumar model, we find that these results, to a large degree, are driven by firms committing the largest frauds, where the degree of fraud is measured by the size of the subsequent earnings restatement deflated by the firm's assets. Our results for the Basu model are weaker. We find that according to the Basu model, fraud firms become more conservative than non-fraud firms in post-fraud period. However, when we also split our sample by magnitude of fraud-related restatement, we find that the Basu model identifies fraud firms as anti-conservative as compared to pre-fraud period. However, with respect to post-fraud period, we find that the Basu model shows a decline in conservatism of fraud firm, which is inconsistent with our expectations and the results of Ball and Shivakumar model. Thus, these results suggest that the Ball and Shivakumar model is a more powerful test of firm's conservatism, at least when it comes to distinguishing fraud firms from non-fraud firms.

Our results are important for the overall debate on measurement of accounting conservatism which has risen more actively in the recent years. Furthermore, our results are also important for policy-makers who are debating the merits of greater conservatism for capital markets (Watts, 2003). 


\section{References:}

Ball, R. and S.P. Kothari (2008). Econometrics of the Basu Asymetric Timeliness Coefficient and Accounting Conservatism. Working Paper, U of Chicago and MIT

Ball, R. and L. Shivakumar (2007). Earnings Quality at Initial Public Offerings. Journal of Accounting and Economics, forthcoming.

Ball, R., R. Bushman and F. Varvari (2007). The Debt-Contracting Value of Accounting Information and Loan Syndicate Structure. Working Paper, University of North Carolina.

Bartov, E., D. Givoly and C. Hayn (2002). The rewards to meeting or beating earnings expectations. Journal of Accounting and Economics, 33(2), 173-204

Basu, S. (1997). The conservatism principle and the asymmetric timeliness of earnings. Journal of Accounting and Economics, 24(1), 3-37

Beasley, M., J. Carcello, and D. Hermanson. (1999). Fraudulent Financial Reporting: 1987 1997 An Analysis of U.S. Public Companies. Committee of Sponsoring Organizations of the Treadway Commission.

Beaver, W. and S. Ryan (2005). Conditional and Unconditional Conservatism:

Concepts and Modeling. Review of Accounting Studies, 10, 269-209

Beneish.M. 1999. The detection of earnings manipulation. Financial Analyst Journal 24-36.

Dietrich, R., K. Mueller, E. Riedl (2007). Asymmetric timeliness tests of accounting conservatism. Review of Accounting Studies, 12(1), 95-124

Farber, D.B.(2005). Restoring trust after fraud: Does corporate governance matter? The Accounting Review 80, 539-561.

García Lara, J.M., García Osma, B., and Penalva, F. (2007). Accounting Conservatism and Corporate Governance. Review of Accounting Studies

Givoly, D. and C. Hayn (2000). The changing time-series properties of earnings, cash flows and accruals: Has financial reporting become more conservative? Journal of Accounting and Economics, 29, 287-320

Givoly, D., C. Hayn, A. Natarajan (2007). Measuring reporting conservatism. The Accounting Review, 82(1), 65-106

Hayn, C. (1995). The information content of losses. Journal of Accounting and Economics, 20(2), $125-153$ 
Jones, K., G. Krishnan and K. Melendrez (2008). Do Models of Discretionary Accruals Detect Actual Cases of Fraudulent and Restated Earnings? An Empirical Evaluation. Forthcoming in Contemporary Accounting Research.

Khan, M. and R. Watts (2007). Estimation and Validation of a Firm-Year Measure of Conservatism. Working Paper. MIT.

Loebbecke, J., M. Eining, and J. Willingham. 1989. Auditors' experience with material irregularities: Frequency, nature, anddetectability. Auditing: A Journal of Practice \& Theory 9 (Fall): 1-28.

Moerman, R. (2006). The role of information asymmetry and financial reporting quality in debt contracting: Evidence from the secondary loan market. Working Paper. University of Pennsylvania.

Petersen (2007). Estimating standard errors in finance panel data sets: comparing approaches. Forthcoming, Review of Financial Studies.

Rosner, R. (2003). Earnings manipulation in failing firms. Contemporary Accounting Research, 20(2), 361-408

Roychowdhury, S. and R. Watts (2007). Asymmetric timeliness of earnings, market-to-book and conservatism in financial reporting. Journal of Accounting and Economics, 44(1), 2-32.

Watts, R. (2003). Conservatism in Accounting Part II: Evidence and Research Opportunities. Accounting Horizons 17 No. 4 (2003): 287-301 


\section{Appendix A}

Frauds from COSO's Report on Fraudulent Financial Reporting

from 1987-1997

Total number of firms identified from Accounting and Auditing Enforcement

Releases (AAERs) attributable to alleged or actual accounting fraud

(non-duplicates) issued since COSO's 1987-1997 Report on Fraudulent

Financial reporting

Additional Frauds identified through other sources (e.g. popular press search and AAA Monograph on litigation involving Big Four auditors and their predecessor firms)

Total

Firms with either no data or missing data on Compustat, Edgar, or

Lexis/Nexis (e.g. small or foreign firms)

Frauds related to quarterly (10-Q's) but not annual data (10-K's)

Frauds dropped for other reasons (e.g. financial services or insurance firms, fraud had no affect earnings, or very little information available about fraud)

Total fraud sample

Total number of fraud-year observations (average fraud lasted 2 years)

Total number of fraud-year observations with restated earnings data

$252 *$

*The fraud sample is matched with all non-fraud firms that have the same two-digit SIC codes. Different tests use different sample periods so the number of observations used in the tests vary. 


\section{Appendix B \\ Variables' Definitions}

\section{Variable Definition}

\section{Variables used in our analyses:}

TA A firm's total accruals, deflated by the prior period total assets. Total accruals are estimated using Sloan (1996) approach for all firms prior to 1988 and using Collins and Hribar (2000) approach for all firms in post 1988 period.

EARN A firm's earnings before extraordinary items (data18), deflated by the prior period total assets.

CF (Earn-TA).

D An indicator variable for bad news. In Ball and Shivakumar model, $\mathrm{D}=1$ if $\mathrm{CF}<0$, and 0 otherwise. In Basu model, $\mathrm{D}=1$ if Ret $<0$ and 0 otherwise.

FRAUDPRD An indicator variable that equals 1 if the year represents a pre-fraud year, 0 if the year is a fraud year and 2 if the year is after the fraud year.

FRAUDFRM An indicator variable that equals 1 if the firm is a fraud firm; 0 otherwise

RET Buy and hold stock return, cumulated starting three months after the beginning of a firm's fiscal year, and until three months after the end of a firm's fiscal year.

RESTATEH An indicator variable that equals 1 if the restated income (i.e., difference between originally reported earnings and restated earnings) is higher than the median restated income. This difference is deflated by the average assets of a firm.

Variables reported for descriptive statistics only:

BHAR Buy and hold size adjusted abnormal return, cumulated starting three months after the beginning of a firm's fiscal year, and until three months after the end of a firm's fiscal year.

NOA A firms's net operating assets (see Hershleifer et al. (2004), deflated by prior period assets.

DEBT A firm's total liabilities (data181), deflated by the sum of its market value of equity and total liabilities.

LMVE $\quad \log ($ market value of equity+1). Market value of equity is data $25 *$ data199

PE Ratio of share price to earnings per share. 
Table 1

\section{Descriptive statistics}

This table reports descriptive statistics for a sample of fraud firms from Jones et al (2008) and a sample of matched control firms (on year and 2 digit SIC code) during pre-fraud period, fraud period, and post-fraud period. All variables are defined in the Appendix.

\begin{tabular}{|c|c|c|c|c|c|c|c|c|c|c|c|c|}
\hline \multicolumn{5}{|c|}{ Fraud Firms Pre-fraud period } & \multicolumn{4}{|c|}{ Fraud Firms Fraud Period } & \multicolumn{4}{|c|}{ Fraud Firms Post-Fraud Period } \\
\hline Variable & $\mathbf{N}$ & Mean & $\begin{array}{l}\text { Std } \\
\text { Dev }\end{array}$ & Median & $\mathbf{N}$ & Mean & $\begin{array}{l}\text { Std } \\
\text { Dev }\end{array}$ & Median & $\mathbf{N}$ & Mean & $\begin{array}{l}\text { Std } \\
\text { Dev }\end{array}$ & Median \\
\hline TA & 505 & 0.00 & 0.24 & -0.01 & 298 & -0.01 & 0.28 & -0.02 & 419 & -0.11 & 0.21 & -0.08 \\
\hline EARN & 443 & 0.02 & 0.21 & 0.06 & 289 & 0.00 & 0.21 & 0.04 & 415 & -0.12 & 0.30 & -0.03 \\
\hline $\mathrm{CF}$ & 505 & 0.00 & 0.34 & 0.06 & 298 & -0.04 & 0.57 & 0.03 & 419 & 0.02 & 0.16 & 0.03 \\
\hline RET & 431 & 0.37 & 0.76 & 0.24 & 283 & 0.15 & 0.94 & -0.07 & 413 & 0.03 & 0.94 & -0.14 \\
\hline BHAR & 431 & 0.19 & 0.62 & 0.07 & 283 & 0.02 & 0.73 & -0.15 & 414 & -0.11 & 0.71 & -0.22 \\
\hline NOA & 462 & 0.91 & 0.77 & 0.80 & 279 & 1.07 & 1.61 & 0.84 & 393 & 0.46 & 2.04 & 0.52 \\
\hline DEBT & 500 & 0.34 & 0.23 & 0.29 & 305 & 0.37 & 0.25 & 0.35 & 422 & 0.45 & 0.25 & 0.43 \\
\hline LMVE & 502 & 5.11 & 2.34 & 4.80 & 305 & 5.56 & 2.49 & 5.15 & 422 & 5.43 & 2.27 & 5.14 \\
\hline PE & 505 & 4.07 & 16.98 & 1.05 & 306 & 2.10 & 13.03 & 0.51 & 419 & 3.06 & 56.55 & -0.01 \\
\hline \multicolumn{5}{|c|}{ Non Fraud Firms Pre-fraud period } & \multicolumn{4}{|c|}{ Non-Fraud Firms Fraud Period } & \multicolumn{4}{|c|}{$\begin{array}{c}\text { Non-Fraud Firms Post-Fraud } \\
\text { Period } \\
\end{array}$} \\
\hline Variable & $\mathbf{N}$ & Mean & $\begin{array}{l}\text { Std } \\
\text { Dev }\end{array}$ & Median & $\mathbf{N}$ & Mean & $\begin{array}{l}\text { Std } \\
\text { Dev }\end{array}$ & Median & $\mathbf{N}$ & Mean & $\begin{array}{l}\text { Std } \\
\text { Dev }\end{array}$ & Median \\
\hline TA & 32,087 & -0.04 & 0.20 & -0.04 & 14,423 & -0.08 & 0.45 & -0.04 & 35,843 & -0.08 & 0.41 & -0.05 \\
\hline EARN & 32,223 & 0.01 & 0.25 & 0.06 & 15,105 & -0.01 & 0.27 & 0.05 & 37,141 & -0.04 & 0.29 & 0.04 \\
\hline $\mathrm{CF}$ & 32,083 & 0.01 & 0.32 & 0.06 & 14,422 & -0.04 & 0.52 & 0.06 & 35,841 & -0.03 & 0.43 & 0.06 \\
\hline RET & 31,861 & 0.16 & 0.59 & 0.08 & 14,760 & 0.27 & 0.96 & 0.08 & 36,105 & 0.14 & 0.72 & 0.04 \\
\hline BHAR & 31,877 & 0.00 & 0.47 & -0.06 & 14,779 & 0.07 & 0.71 & -0.05 & 36,138 & -0.02 & 0.53 & -0.09 \\
\hline NOA & 32,097 & 2.98 & 388.99 & 0.70 & 15,176 & 1.05 & 20.36 & 0.64 & 36,318 & 1.25 & 51.35 & 0.62 \\
\hline DEBT & 35,538 & 0.42 & 0.28 & 0.39 & 16,553 & 0.40 & 0.28 & 0.36 & 39,496 & 0.40 & 0.28 & 0.35 \\
\hline LMVE & 35,597 & 4.22 & 1.98 & 4.01 & 16,571 & 4.66 & 2.09 & 4.45 & 39,561 & 4.93 & 2.12 & 4.77 \\
\hline PE & 35,546 & 4.10 & 62.58 & 1.11 & 16,579 & 4.07 & 86.97 & 0.75 & 39,566 & 2.63 & 67.64 & 0.39 \\
\hline
\end{tabular}




\section{Table 2}

\section{Conservatism in Fraud Firms: Ball and Shivakumar (2006) model}

\section{Panel A: Matched sample}

This panel reports the results of the following OLS regressions of a matched sample of fraud firms from Jones et al (2008) matched against all other firms in the same year and in the same 2 digit SIC code:

$T A=\alpha_{0}+\alpha_{1} D C F+\alpha_{2} C F+\beta \alpha_{3} D C F * C F+\alpha_{4} F R A U D P R D+\alpha_{5} F R A U D F R M+\alpha_{6} C F * D C F * F R A U D P R D+\alpha_{7} C F * D C F * F R A U D F R M$

$$
+\alpha_{8} C F * D C F * F R A U D P R D * F R A U D F R M+\gamma
$$

The sample period encompasses five years before the fraud period, and five year after, for all firm years with sufficiently available data. All variables are defined in The Appendix. The year dummies that are not reported, and all standard errors are cluster-adjusted per Petersen (2007). *, **, *** denote two-tail significance levels of $0.1,0.05$, and 0.01 , respectively.

\begin{tabular}{|c|c|c|c|c|c|c|c|c|c|}
\hline & \multicolumn{2}{|c|}{$\begin{array}{c}\text { Pre-fraud period vs. } \\
\text { fraud period }\end{array}$} & & \multicolumn{2}{|c|}{$\begin{array}{l}\text { Fraud period vs. } \\
\text { post-fraud period }\end{array}$} & \multicolumn{3}{|c|}{$\begin{array}{l}\text { Pre-fraud period vs. } \\
\text { post-fraud period }\end{array}$} & \\
\hline & Estimate & t Value & & Estimate & t Value & & Estimate & t Value & \\
\hline Intercept & 0.04 & 9.48 & $* * *$ & 0.02 & 1.07 & & 0.04 & 5.02 & $* * *$ \\
\hline $\mathrm{CF}$ & -0.61 & -18.93 & $* * *$ & -0.98 & -11.99 & $* * *$ & -0.82 & -13.49 & $* * *$ \\
\hline $\mathrm{DCF}$ & 0.05 & 7.59 & $* * *$ & 0.08 & 5.68 & $* * *$ & 0.06 & 5.89 & $* * *$ \\
\hline $\mathrm{DCF}^{*} \mathrm{CF}$ & 0.70 & 18.67 & $* * *$ & 1.33 & 11.78 & $* * *$ & 0.94 & 14.66 & $* * *$ \\
\hline FRAUDPRD & 0.05 & 11.88 & $* * *$ & 0.03 & 4.29 & $* * *$ & 0.04 & 16.74 & $* * *$ \\
\hline FRAUDFRM & 0.02 & 1.53 & & -0.05 & -3.36 & $* * *$ & -0.03 & -2.7 & $* * *$ \\
\hline DCF*CF* FRAUDPRD & 0.52 & 13.97 & $* * *$ & 0.29 & 6.06 & $* * *$ & 0.40 & 21.66 & $* * *$ \\
\hline DCF*CF*FRAUDFRM & -0.36 & -6.53 & $* * *$ & -1.15 & -6.48 & $* * *$ & -0.40 & -7.16 & $* * *$ \\
\hline DCF*CF*FRAUDPRD*FRAUDFRM & -0.23 & -2.6 & $* * *$ & 0.54 & 3.91 & $* * *$ & 0.16 & 2.45 & $* *$ \\
\hline Adjusted $\mathrm{R}^{2}$ & & 0.3 & & & 0.38 & & & 0.38 & \\
\hline Number of observations & & 69,846 & & & 77,869 & & & 103,103 & \\
\hline
\end{tabular}




\section{Table 2}

\section{Conservatism in Fraud Firms: Ball and Shivakumar (2006) model}

\section{Panel B: Restatement Size-Fraud firms only}

This panel reports the results of the following OLS regressions of a sample of fraud firms from Jones et al (2008):

$T A=\alpha_{0}+\alpha_{1} D C F+\alpha_{2} C F+\alpha_{3} D C F * C F+\alpha_{4} F R A U D P R D+\alpha_{6} R E S T A T E H+\alpha_{6} D C F * C F * F R A U D P R D+\alpha_{7} C F * D C F * F R A U D P R D * R E S T A T E H+\gamma$ he sample period encompasses five years before the fraud period, and five year after, for all firm years with sufficiently available data. All variables are defined in The Appendix. The year dummies are not reported, and all standard errors are cluster-adjusted per Petersen (2007). *, **, *** denote two-tail significance levels of $0.1,0.05$, and 0.01 , respectively.

\begin{tabular}{|c|c|c|c|c|c|c|c|c|c|}
\hline & \multicolumn{2}{|c|}{$\begin{array}{l}\text { Pre-fraud period } \\
\text { vs. fraud period }\end{array}$} & & \multicolumn{2}{|c|}{$\begin{array}{l}\text { Fraud period vs. } \\
\text { post-fraud period }\end{array}$} & \multicolumn{3}{|c|}{$\begin{array}{l}\text { Pre-fraud period vs. } \\
\text { post-fraud period }\end{array}$} & \\
\hline & Estimate & t Value & & Estimate & t Value & & Estimate & t Value & \\
\hline Intercept & -0.17 & -7.09 & $* * *$ & 0.14 & 2.77 & $* * *$ & 0.08 & 3.22 & $* * *$ \\
\hline $\mathrm{CF}$ & -0.46 & -8.15 & $* * *$ & -0.45 & -2.4 & $* * *$ & -0.52 & -7.00 & $* * *$ \\
\hline $\mathrm{DCF}$ & 0.00 & 0.11 & & 0.05 & 1.44 & & -0.03 & -0.87 & \\
\hline $\mathrm{CF}^{*} \mathrm{DCF}$ & -0.22 & -1.01 & & 0.01 & 0.03 & & -0.15 & -0.67 & \\
\hline FRAUDPRD & 0.04 & 1.43 & & -0.08 & -3.74 & $* * *$ & -0.04 & -3.59 & $* * *$ \\
\hline RESTATEH & -0.08 & -1.69 & & 0.00 & 0.08 & & -0.04 & -1.05 & \\
\hline DCF*CF* FRAUDPRD & 0.76 & 3.75 & $* * *$ & 0.50 & 1.3 & & 0.21 & 1.39 & \\
\hline DCF*CF*FRAUDPRD*RESTATEH & -0.83 & -3.84 & $* * *$ & -0.17 & -1.17 & & 0.35 & 1.84 & $*$ \\
\hline Adjusted $\mathrm{R}^{2}$ & & 0.41 & & & 0.14 & & & 0.45 & \\
\hline Number of observations & & 847 & & & 749 & & & 1,000 & \\
\hline
\end{tabular}




\section{Table 3}

\section{Conservatism in Fraud Firms: Basu (1996) model}

\section{Panel A: Matched Sample}

This panel reports the results of the following OLS regressions of a matched sample of fraud firms from Jones et al. (2008) matched against all other firms in the same year and in the same 2 digit SIC code:

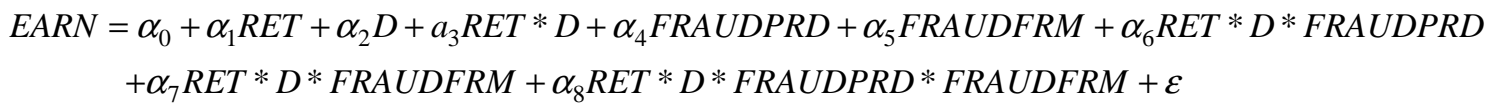

The sample period encompasses five years before the fraud period, and five year after, for all firm years with sufficiently available data. All variables are defined in The Appendix. The year dummies that are not reported, and all standard errors are cluster-adjusted per Petersen (2007). *, **, *** denote two-tail significance levels of $0.1,0.05$, and 0.01 , respectively.

\begin{tabular}{|c|c|c|c|c|c|c|c|c|c|}
\hline & \multicolumn{2}{|c|}{$\begin{array}{l}\text { Pre-fraud period } \\
\text { vs. fraud period }\end{array}$} & \multicolumn{3}{|c|}{$\begin{array}{l}\text { Fraud period vs. } \\
\text { post-fraud period }\end{array}$} & \multicolumn{3}{|c|}{$\begin{array}{l}\text { Pre-fraud period } \\
\text { vs. post-fraud } \\
\text { period }\end{array}$} & \\
\hline & Estimate & t-value & & Estimate & t-value & & Estimate & t-value & \\
\hline Intercept & 0.17 & 46.76 & $* * *$ & 0.12 & 17.39 & $* * *$ & 0.16 & 45.18 & $* * *$ \\
\hline RET & 0.00 & -0.51 & & -0.03 & -10.28 & $* * *$ & -0.02 & -6.18 & $* * *$ \\
\hline $\mathrm{D}$ & -0.01 & -1.69 & $*$ & -0.01 & -3.94 & $* * *$ & -0.02 & -5.58 & $* * *$ \\
\hline RET*D & 0.43 & 33.62 & $* * *$ & 0.34 & 12.17 & $* * *$ & 0.45 & 36.52 & $* * *$ \\
\hline FRAUDPRD & -0.02 & -4.68 & $* * *$ & 0.00 & -1.56 & & -0.01 & -9.37 & $* * *$ \\
\hline FRAUDFRM & 0.00 & 0.27 & & -0.02 & -1.17 & & -0.03 & -2.27 & $* *$ \\
\hline RET*D*FRAUDPRD & -0.12 & -7.34 & $* * *$ & 0.04 & 2.47 & & -0.03 & -5.23 & $* * *$ \\
\hline RET*D*FRAUDFRM & -0.10 & -1.17 & & -0.34 & -2.26 & $* *$ & -0.16 & -1.87 & $*$ \\
\hline RET*D*FRAUDPRD*FRAUDFRM & 0.00 & -0.06 & & 0.17 & 2.20 & $* *$ & 0.07 & 1.63 & \\
\hline Adjusted $\mathrm{R}^{2}$ & & 0.15 & & & 0.12 & & & 0.15 & \\
\hline Number of observations & & 45,683 & & & 51,017 & & & 67,938 & \\
\hline
\end{tabular}




\section{Table 3}

\section{Conservatism in Fraud Firms: Basu (1996) model}

\section{Panel B: Restatement Size-Fraud firms only}

This panel reports the results of the following OLS regressions of a sample of fraud firms from Jones et al. (2008):

EARN $=\alpha_{0}+\alpha_{1} R E T+\alpha_{2} D+a_{3} R E T * D+\alpha_{4} F R A U D P R D+\alpha_{5} R E S T A T E H+\alpha_{6} R E T * D * F R A U D P R D+\alpha_{7} R E T * D * F R A U D O R D * R E S T A T E H+\varepsilon$

The sample period encompasses five years before the fraud period, and five year after, for all firm years with sufficiently available data. All variables are defined in The Appendix. The year dummies that are not reported, and all standard errors are cluster-adjusted per Petersen (2007). *, **, *** denote two-tail significance levels of $0.1,0.05$, and 0.01 , respectively.

\begin{tabular}{|c|c|c|c|c|c|c|c|c|c|}
\hline \multirow[b]{2}{*}{ Parameter } & \multicolumn{2}{|c|}{$\begin{array}{l}\text { Pre-fraud period vs. } \\
\text { fraud period }\end{array}$} & \multicolumn{3}{|c|}{$\begin{array}{l}\text { Fraud period vs. } \\
\text { post-fraud period }\end{array}$} & \multicolumn{3}{|c|}{$\begin{array}{c}\text { Pre-fraud period } \\
\text { vs. post-fraud } \\
\text { period }\end{array}$} & \\
\hline & Estimate & t-value & & Estimate & t-value & & Estimate & t-value & \\
\hline Intercept & -0.16 & -2.69 & $* * *$ & 0.21 & 3.35 & $* * *$ & 0.16 & 4.31 & $* * *$ \\
\hline RET & -0.04 & -1.56 & & 0.00 & -0.04 & & -0.01 & -0.61 & \\
\hline $\mathrm{D}$ & 0.00 & -0.16 & & 0.01 & 0.25 & & -0.01 & -0.33 & \\
\hline $\mathrm{RET}^{*} \mathrm{D}$ & 0.37 & 3.31 & $* * *$ & 0.23 & 1.19 & & 0.29 & 2.54 & $* * *$ \\
\hline FRAUDPRD & -0.01 & -0.31 & & -0.09 & -3.09 & $* * *$ & -0.06 & -3.41 & $* * *$ \\
\hline RESTATEH & 0.00 & -0.06 & & 0.05 & 1.28 & & 0.00 & 0.03 & \\
\hline RET*D*FRAUDPRD & 0.00 & -0.09 & & 0.01 & 0.56 & & 0.02 & 0.39 & \\
\hline RET*D* FRAUDPRD*RESTATEH & -0.30 & -2.41 & $* * *$ & -0.07 & -1.55 & & -0.09 & -1.97 & $* *$ \\
\hline Adjusted $\mathrm{R}^{2}$ & & 0.17 & & & 0.2 & & & 0.19 & \\
\hline Number of observations & & 750 & & & 703 & & & 893 & \\
\hline
\end{tabular}

